\title{
ACESSO À JUSTIÇA: DIREITO DOS ANIMAIS
}

\author{
ACCESS TO JUSTICE: ANIMALS RIGHT
}

Ingrid de Lima Barbosa ${ }^{1}$

\section{RESUMO}

Não podendo o Estado de Direito reconhecer direitos sem fornecer o mecanismo necessário ao exercício e salvaguarda desses perante ele mesmo, o acesso à justiça é previsto constitucionalmente por se revestir dos aspectos de um direito fundamental para a manutenção da vida em sociedade. Porém, esse direito nem sempre apresentou a mesma conotação, sendo, assim, como muitos outros, interpretado diferentemente no decorrer do tempo, agregando, com o avançar da sociedade, novos aspectos e sujeitos-titulares. De fato, aos poucos, pessoas que não gozavam de capacidade jurídica a adquiriram, como os negros. Atualmente, a discussão se centra sobre a consideração moral e jurídica dos animais, o que remete ao acesso à justiça como um direito-consequência da atribuição de direitos já previstos no ordenamento. Portanto, no presente artigoforam analisados os critérios-chave da capacidade jurídica no Direito brasileiro, e verificada a solidez da possibilidade do reconhecimento da capacidade jurídica dos animais, com o instrumental metodológico dedutivo. A perspectiva extraída da pesquisa foi a de que, a partir do tecnicismo do conceito jurídico de pessoa/sujeito de direito e de algum suporte na teoria dos casos marginais, não há óbice concreto ao reconhecimento da capacidade de ser parte dos animais, embora não sejam capazes de estar em juízo, devendo ser representados ou substituídos, conforme disciplina a legislação.

Palavras-chave:Acesso à justiça. Capacidade jurídica. Animais.

\section{ABSTRACT}

As the Rule of Law can not recognize rights without providing the necessary mechanism for exercising and safe guarding them before it self, access to justice is constitutionally provided for as it covers aspects of a fundamental right for life in society. However, this right did not always have the same connotation, and thus, like many others, it was interpreted differently over

\footnotetext{
${ }^{1}$ Técnica em Controle Ambiental pelo Instituto Federal de Educação, Ciência e Tecnologia do Rio Grande do Norte - IFRN (2010-2014). Bacharel em Direito pela Universidade Federal do Rio Grande do Norte - UFRN (2014-2018). Mestranda em Constituição e Garantias de Direitos pela Universidade Federal do Estado do Rio Grande do Norte UFRN (2019-). Advogada (OAB/RN 17.437).

${ }^{2}$ Possui Graduação em Direito pela Universidade Federal da Bahia - UFBA (1976), Mestrado em Direito pela Pontifícia Universidade Católica de São Paulo - PUC/SP (1998) e Doutorado em Direito pela Faculdade Autônoma de Direito de São Paulo - FADISP (2011). Atualmente é Professor Associado da Universidade Federal do Rio Grande do Norte e Chefe do Departamento de Direito Processual e Propedêutica - DEPRO desta mesma instituição. Docente permanente no Programa de Pós-graduação em Direito, curso de Mestrado em Direito e Programa de Pósgraduação em Gestão de Processos Institucionais, Mestrado Profissional, da UFRN. Possui experiência na área de Direito Público, Acesso à Justiça, Teoria Geral do Processo. Coordenador da Base de Pesquisa em Processo e Acesso a Justiça junto a UFRN. Presidente da Comissão de Mediação da UFRN. Magistrado aposentado.
} 
time, adding new aspects and right-holders. In fact, through out the evolution of society, people who did not have the legal capacity acquired it, like black people. Currently, the discussion focuses on the moral and legal consideration of animals, which refers to access to justice as a consequence of the attribution of rights already provided for in the order. Therefore, in this article, the key criteria of legal capacity in brazilian Law were analyzed, and the solidity of the possibility of recognizing the legal capacity of animals was verified, with the deductive methodological instruments. The perspective extracted from there search was that, based on the technicality of the legal concept of person/subject to flaw and some support in the theory of marginal cases, there is no concrete obstacle to there cognition of the ability to be part of animals, although they are notable to be in court, and must be represented or replaced, according to the legislation.

Keywords: Access to justice. Legal capacity. Animals.

\section{INTRODUÇÃO}

De acordo com o artigo 70 do Código de Processo Civil, toda pessoa que esteja em exercício de seus direitos goza de capacidade para pleitear em juízo. E sobre os aspectos jurídicos do termo pessoa na ordem civil brasileira, o artigo $1^{\circ}$ do Código Civil explicita que toda pessoa é titular de direitos e deveres. Em ambos os casos, "pessoa" não é um termo jurídico relacionado exclusivamente ao gênero humano.

Para o Direito, "pessoa" é a figura jurídica capaz de estabelecer relações jurídicas a partir de direitos e deveres outorgados pelo próprio sistema jurídico. Então, ser considerado "pessoa" em determinado ordenamento não depende exclusivamente do sistema biológico ou da capacidade de raciocinar autonomamente. Além dos seres humanos, são pessoas para o Direito brasileiro as empresas e universalidades despersonificadas, que, ao fim e ao cabo, são expressões patrimoniais.

De fato, há não muito tempo, nem os negros, nem as mulheres, eram consideradas pessoas no termo jurídico da palavra. Assim, não tinham direitos, nem capacidade jurídica para pleitear algo perante o Judiciário. Logo, se o parâmetro para a atribuição de capacidade de direito e de dever fosse pautado no sistema biológico ou na capacidade de raciocinar, a situação acima seria inexplicável, dada a impossibilidade de se provar a ausência de razão ou de sistema biológico quanto aos negros e às mulheres.

Neste diapasão, surge um questionamento: é possível ainda sustentar que a capacidade jurídica no Direito está calcada em pressupostos básicos e anteriores à disposição de vontade do Estado?

Com o avançar da modernidade rumo a novos contextos sociais, esse questionamento se tornou cada vez mais premente de solução. Afora a constituição de novos arranjos empresariais e 
o surgimento de situações que demandam o exercício do direito patrimonial de forma direta, como no caso da herança jacente, os animais passaram a gozar de interesses para além do campo moral.

A Constituição Federal de 1988, à guisa de exemplo, consagrou a proteção dos animais contra a prática de maus-tratos, o que levou à edição de normas infraconstitucionais que vieram a regulamentar quais seriam essas formas de maus-tratos e como se daria a proteção daqueles seres.

Frente a isso, para a doutrina animalista se tornou insustentável compreender que os animais teriam direito a não serem tratados com crueldade, mas não poderiam pleitear em Juízo quaisquer reparos ou o cumprimento da norma constitucional ou infraconstitucionalprotetiva, por não gozarem do status de pessoa. Se a entes compostos eminentemente por riquezas materiais é conferida a capacidade jurídica, por que não aos animais, que são seres vivos, dotados de senciência e consciência?

É a partir desse contexto que o presente artigo extrai a sua atualidade e pertinência, com foco no diálogo entre os pressupostos processuais para a formalização da lide perante o Judiciário e a conformação do direito material frente aos anseios de direitos em favor dos animais. A hipótese, portanto, é a de que não há empecilhos para a atribuição de capacidade jurídica aos animais, uma vez que a capacidade de direitos e deveres se adequa a cada ente que o Direito reconhece como sujeito de direitos.

Nessa esteira de raciocínio, o objetivo que se pretende alcançar é o de analisar os critérios para a atribuição de capacidade jurídica e verificar a solidez da possibilidade do reconhecimento da capacidade jurídica dos animais, no Direito brasileiro. Para a sua concretização, o método empregado é o dedutivo.

$\mathrm{O}$ artigo se divide em três partes. A primeira aborda o acesso à justiça como um direito fundamental e as suas premissas. A segunda traz a análise dos critérios processuais para a verificação da capacidade de ser parte no Direito brasileiro. Por fim, na terceira parte é analisada a premissa do acesso à justiça como direito dos animais também.

\section{ACESSO À JUSTIÇA: DIREITO FUNDAMENTAL}

$\mathrm{O}$ artigo $5^{\circ}, \mathrm{XXXV}$, da Constituição Federal traz no rol de direitos fundamentais o intitulado "acesso à justiça", o qual está assim disposto: "a lei não excluirá da apreciação do Poder Judiciário lesão ou ameaça a direito;”. E, considerando o caput do artigo $5^{\circ}$, esse direito é 
garantido a "todos", que são considerados iguais perante a lei (BRASIL, 1988).Essa disposição, da forma como se lê, representa grande avanço na luta histórica por direitos.

Com efeito, Lorena Miranda Santos Barreiros (2009, p. 2) salienta que o conceito de acesso à justiça não foi unívoco no decorrer dos tempos, e, igualmente, não apresenta a mesma conotação em todos os lugares. Juvêncio Borges Silva (2013, p. 481), nesse sentido, relembra que nos países em que mais se desenvolveu o estigma da escravidão, as diferenças entre os cidadãos se refletiram no exercício de direitos, e, assim, no acesso à justiça, de modo que esse direito deve ser compreendido como inserido no contexto de dominação e privilégios.

$\mathrm{E}$, assim, é fato que o conceito de acesso à justiça tem apresentado evoluções no decorrer das transformações sociais. Mauro Cappelletti e Bryant Garth (1988, p. 9, 11-12) bem exemplificam esse fenômeno, aduzindo que, nos séculos XVIII e XIX, nas sociedades burguesas, o acesso à justiça estava mais relacionado ao direito privado, de forma que refletia apenas o direito formal de um indivíduo demandar alguém ou ser demandado. Todavia, na sociedade contemporânea, a garantia do acesso efetivo tem se destacado diante dos novos direitos individuais e sociais, uma vez que não há sentido em titularizar direitos se não é possível reivindicá-los.

A evolução do conceito de acesso à justiça alçou patamar que transformou, inclusive, a forma como é vista a imprescindibilidade do Poder Judiciário na solução de contendas. A interpretação desse direito foi além da mera formalidade e passou a garantir a substancialidade: a celeridade, a efetividade e a adequação da prestação estatal. Dessa forma, surgiram novas formas de garantir a solução do litígio, ao mesmo tempo em que o Judiciário deixou de ser o fim do acesso à justiça (BARREIROS, 2009, p. 3).

Neste contexto, o direito de ação pode ser conceituado como um direito fundamental, que assegura aos cidadãos a concretização de seus outros direitos através do acesso ao Poder Judiciário, mas não somente a ele, e à prestação jurisdicional revestida das características necessárias ao pleno exercício da cidadania (BARREIROS, 2009, p. 4-5). É um verdadeiro direito subjetivo que se exerce contra o Estado (LIMA, 1999, p. 71).

Conforme apontam Ingo Wolfgang Sarlet, Luiz Guilherme Marinoni e Daniel Mitidiero (2015), o Estado de Direito não poderia se limitar a ser um Estado que somente reconhece direitos fundamentais, deixando de garanti-los, inclusive em face dele mesmo. Por isso, a Constituição Federal, além de assegurar a independência do Poder Judiciário e de seus componentes, firmou a inafastabilidade do controle judicial da lesão ou ameaça de lesão a direito, bem como a assistência judiciária, com a Advocacia Pública e a assistência judiciária gratuita. 
Diante desse quadro de garantias, importa salientar que o comando constitucional acima exposto se dirige diretamente (e principalmente, mas não exclusivamente) ${ }^{3}$ ao Poder Legislativo, uma vez que o âmbito de alcance desse direito constitucional não pode ser limitado por qualquer ato normativo (TAVARES, 2020). Todavia, George Marmelstein Lima (1999, p. 80-157) destaca que, como um direito fundamental que é, o acesso à justiça não é absoluto, logo, apresenta algumas limitações, como quanto às questões de competência da Justiça Desportiva e às punições disciplinares dos militares. Além dessas, é possível erigir como limitação as condições da ação.

Quanto a esse último caso, o jurista ressalta que para ser conferida resposta satisfatória ao pleito formulado em Juízo é preciso que haja o cumprimento dos requisitos formais-processuais, como legitimidade e interesse. Em contrapartida, não pode o Juízo se ater a formalidades desnecessárias, analisando se no caso concreto a única solução cabível é a extinção, ou se é possível ordenar a emenda à petição inicial, e, assim, permitir a correção da irregularidade (LIMA, 1999, p. 122, 124). Efetivamente, José Joaquim Gomes Canotilho (2003,p. 498) destaca que a prestação jurisdicional não pode restar comprometida em razão da exigência de pressupostos desproporcionais.

Da imbricação entre direitos fundamentais e direito de acesso à justiça, é possível extrair que o núcleo desse último está contido no dever do Estado de promover a proteção jurisdicional dos direitos materiais. Por isso, havendo excessiva dificuldade no controle judicial de uma violação, de modo que o detentor do direito se sinta desprovido de qualquer via de eleição protetiva, estará configurada a lesão ao direito de ação (CANOTILHO, 2003,p. 497).

Por fim, importa mencionar que o direito de ação engloba não só lesão ou ameaça de lesão a direito, como também a interesses legítimos, que são aqueles que, embora não consagrados como direitos subjetivos, devem ser protegidos pela ação estatal, a exemplo do direito ao meio ambiente ecologicamente equilibrado, que não possui um titular individualizado numa pessoa, mas na coletividade (LIMA, 1999, p. 74).

Estando já em discussão a quinta dimensão de direitos fundamentais (BONAVIDES, 2011, p. 579-593), não é plausível tratar o acesso à justiça somente sob o viés privatista, uma vez que, assim como o direito ao meio ambiente não comporta as minudências dos direitos de

\footnotetext{
${ }^{3}$ O termo "lei" deve ser interpretado extensivamente, para incluir portarias, medidas provisórias, decretos, leis complementares e até emendas constitucionais, que tenham o intuito de excluir a jurisdição do exame de tais matérias (LIMA, 1999, p. 73).

${ }^{4} \mathrm{O}$ direito ao meio ambiente ecologicamente equilibrado pode ser visto sob a ótica de um direito subjetivo quando se analisa que há um sujeito (a coletividade) que é titular do direito à proteção do ambiente (SARLET; FENSTERSEIFER, 2012, p. 57).
} 
liberdade, o direito à paz, à democracia, à informação, e, como recentemente se afirmam, dos animais, são interesses legítimos que devem igualmente ser considerados pelo Poder Judiciário.

Com efeito, especificamente no tocante aos direitos dos animais, Flávio Martins Nunes Júnior afirma, em entrevista ao Jornal Carta Forense, que os animais não-humanos são titulares de direitos fundamentais englobados na quinta dimensão, trazendo consigo controvérsias semelhantes aos direitos das demais dimensões em seu processo de afirmação (CARTA FORENSE, 2017 [online]).

Logo, e retomando o que foi dito ao início, o acesso à justiça não pode abrigar umainterpretação estanque, visto que a forma de exercício dos direitos pelos cidadãos constantemente se amplia, assim como novos sujeitos são reconhecidos, acompanhando as necessidades sociais em suas evoluções e involuções.

\section{DIREITO DE AÇÃO: CAPACIDADE DE SER PARTE}

Segundo o posicionamento de Giuseppe Chiovenda (2009, p. 768), parte é quem ingressa com uma ação em seu próprio nome, ou em favor de quem é ajuizada a demanda a fim de obter a tutela da lei, assim como aquele contra quem a ação é ajuizada. Liebman, por sua vez, entende que parte é o sujeito que participa do contraditório estabelecido pelo juiz (LIEBMAN, 1984,p. 89, apud THEODORO JR., 2014, p. 414). Mesmo sendo o conceito de Liebman mais amplo do que o de Chiovenda, afirma Daniel Amorim Assumpção Neves (2017, p. 137) que parcela da doutrina processualista entende que é possível conciliar ambos os conceitos.

De fato, enquanto Chiovenda afirma ser parte somente aquele que compõe o processo e que está pedindo algo, ou se apresente como alguém contra quem algo está sendo pedido, Liebman disciplina que basta estar inserido na relação processual para ser parte, sendo irrelevante estar pedindo algo ou ter um pedido em seu desfavor. Desse norte, o posicionamento deste último se apresenta mais promissor e mais consentâneo com a atualidade do processo civil.

A despeito dessa divergência, impende registrar que o conceito de parte na relação processual não se confunde com o conceito de parte na relação material. Mesmo que um determinado sujeito não seja parte na relação material poderá ele ser parte na relação processual, o que vai além da sua legitimidade como postulante (NEVES, 2017, p.138).

Caso não haja compatibilidade entre os sujeitos de ambas as relações jurídicas (material e processual), há o que se denomina de ilegitimidade da parte, levando à extinção do processo sem resolução do mérito, consoante disciplina o artigo 485, VI do Código de Processo Civil. A 
excepcionalidade do caso se refere ao permissivo legal para o pleito de terceiro em nome próprio acerca de direito de outrem (MONERAT, 2020,p. 342).

Contudo, para ser considerada parte, a pessoa deve ter capacidade para tanto, não sendo permitido a todos o exercício do direito de ação de forma simples. Com efeito, em se tratando da relação jurídica processual, a capacidade jurídica das partes é vista sob três aspectos: 1) capacidade de ser parte; 2) capacidade de estar em juízo; 3) capacidade postulatória. Para esse estudo somente serão considerados os dois primeiros aspectos.

Segundo José Eduardo Carreira Alvim (2016, p. 167), a capacidade de ser parte se relaciona com a capacidade de ser titular de direitos, o que inclui as pessoas físicas e as pessoas jurídicas; já a capacidade de estar em juízo é aquela referente ao exercício, dos seus direitos, por si mesmo, de modo que quem a possui deverá ter capacidade civil plena. Logo, apesar de algumas partes serem sujeitos de direito, elas não podem exercer diretamente a capacidade de estar em juízo, devendo preencher algumas condições, como a representação ou a assistência. ${ }^{5}$

Como se observa, a capacidade de ser parte é mais ampla do que a capacidade de estar em juízo, como ocorre com os incapazes, que precisam de um representante processual para legitimar o seu pleito. No caso das pessoas jurídicas, sendo uma ficção jurídica, é imperioso haver a presença de uma pessoa física que a represente perante o juiz (ALVIM, 2016, p. 167).

Diante disso, o exercício do direito de ação, embora seja conferido a todos, exige o preenchimento de certos pressupostos legais que limitam a atuação do cidadão frente ao Estado.

Decerto, postular em Juízo exige a concatenação de atos previamente dispostos e a participação daqueles que são os verdadeiramente interessados no deslinde da controvérsia (titulares do direito material). Para tanto, é preciso que a sua atuação no processo seja ampla, assegurado o contraditório, de modo que as desigualdades inerentes à participação da parte (como a incapacidade) sejam mitigadas pela lei.

Nesse sentido, no estudo da capacidade de ser parte e de estar em juízo,é importante tratar das especificidades da capacidade jurídica diferenciando-a da personalidade jurídica. De acordo com Roberto Pinheiro Campos Gouveia Filho (2008, p. 50), toda pessoa tem capacidade de titularizar direitos. Todavia, os entes despersonificados não têm personalidade jurídica, mas apresentam a aptidão genérica para serem sujeitos de direitos, o que se intitula de capacidade jurídica.

No âmbito do direito processual civil, a capacidade de ser parte, portanto, é conferida a todo aquele ente, personalizado (personalidade jurídica) ou não, que tem capacidade jurídica, de

\footnotetext{
${ }^{5} \mathrm{Na}$ representação, atos são realizados pela parte unicamente através do seu representante; já na assistência, o "representante" atuará em conjunto com a parte (NEVES, 2017, p. 167.).
} 
modo que aqueles que não são sujeitos de direito não podem pleitear em juízo.E sendo a relação jurídica aquela que é objeto do processo civil, segundo Carlos Roberto Gonçalves (2012, p. 72)entende-se que somente os seres humanos podem ser sujeitos de tal relação da vida social, uma vez que, apesar de os animais merecerem proteção, não são considerados sujeitos de direitos, por não terem a chamada capacidade de direito. Assim, a ordem jurídica somente reconhece dois tipos de pessoas: as físicas e as jurídicas.

O posicionamento acima tem fundamento na teoria sobre a personalidade jurídica. Conforme Nelson Rosenvald e Cristiano Chaves de Farias (2015, p. 127,130), a dignidade humana [de matriz kantiana] está no centro norteador de tal disposição normativa, elevando o ser humano ao ápice do ordenamento jurídico, haja vista que as normas são feitas para disciplinar as suas relações jurídicas. Neste sentido, as normas gerais e de direito civil, especialmente, devem ressaltar a dignidade do homem.

Ao lado da dignificação humana, e, portanto, da valorização das pessoas físicas na relação jurídica, ao tratar sobre as"pessoas" no Código Civilista, a construção do Direitonão pôde deixar de lado os "entes morais" a quem a lei atribuiu "personalidade jurídica", realidades que surgiram do avançar da sociedade e da necessidade de manutenção da relações sociais. Nesse caminhar de ideias, pessoa é todo sujeito de direito, capaz de titularizar relações jurídicas (FARIAS; ROSENVALD, 2015, p. 132).

Apesar disso, a realidade social impôsque ser sujeitos de direitos não estivesse exclusivamente associadoà personalidade jurídica, uma vez que é possível ser sujeito de direito, mesmo sem personalidade, nisso se incluindo as pessoas jurídicas, verdadeiras ficções legais, e os entes despersonificados (FARIAS; ROSENVALD, 2015, p. 135). Assim, para reclamar direitos e obrigações não é preciso ser uma pessoa no sentido estrito da palavra, basta ser sujeito de direito, e esse status a própria lei pode conferir independentemente de ser um ser humano ou não.Ser humano não é o critério exclusivo para se ter capacidade jurídica, e, assim, ser parte num processo; basta que seja considerado pelo direito como um "ente moral", como afirmam Nelson Rosenvald e Cristiano Chaves de Farias (2015, p. 132).

Nessa esteira de raciocínio, parece impossível conciliar essa ideia com a de que os animais não-humanos, somente por não serem pessoas na acepção kantiana da palavra, não possam ter capacidade jurídica, o que os impediria a poder ser parte em processos.Efetivamente, se até mesmo a massa falida, o condomínio edilício, e a pessoa jurídica são considerados sujeitos de direitos e obrigações, e podem pleitear em juízo, por que não seres vivos que guardam certa semelhança com os homens? Onde restaria a grande incompatibilidade neste caso? 
Logo, se ser parte num processo se relaciona com o interesse em estar em Juízo (Liebman), podendo ser a capacidade jurídica mitigada pela representação, ou, até mesmo pela substituição processual ${ }^{6}$, os animais não-humanos como detentores de direitos (direito a não ser vítima de crueldade - artigo 225, $\S 1^{\circ}$, VII da Constituição Federal), em tese, preenchem os requisitos necessários para serem considerados como seres capazes de ser parte e estar em Juízo.

\section{O DIREITO DE AÇÃO DOS ANIMAIS}

Consoante se observou acima, para ser sujeito de direito ou, especificamente, parte num processo, não precisa necessariamente ser humano, mas, sim, que o Direito, pelas circunstâncias das relações jurídicas, atribua a determinado ente a capacidade jurídica. Em razão disso, ao lado dos seres humanos, as empresas, a massa falida, o condomínio edilício, a herança jacente, adquiriram a capacidade de ser parte em processos.

Num primeiro olhar seria possível afirmar que, embora o Código Civil de 2002 tenha fixado as balizas de um tratamento calcado na dignidade humana e na boa-fé em detrimento do privilégio que a propriedade privada gozava no Código de 1916, a atribuição do status de sujeito de direito guardou ainda os aspectos patrimoniais de outrora.

E isso porque, segundo Fábio Ulhoa Coelho (2012, p. 110), a dinâmica das relações jurídicas demanda a criação de conceitos abstratos para que seja conferida uma "forma jurídica", oportunizando a titularidade de interesses. Nelson Rosenvald e Cristiano Chaves de Farias (2015, p. 331), lembram ainda que a pessoa jurídica é decorrência de uma realidade cultural e social.

Essa discussão se expande quando, Kelsen (1999, p. 120) argumenta que a "pessoa física" é uma criação ficcional do Direito, sendo certo que a"pessoa jurídica” é aquela que está inserida numa relação jurídica. Em seu raciocínio, a pessoa física não se distingue da pessoa jurídica, uma vez que, da mesma forma que essa última não tem por "suporte" o indivíduo, a pessoa física tem por suporte os seus direitos e deveres jurídicos, e não os fatores biológicos ou de racionalidade.

A sustentação desse argumento parte da premissa de que, ao longo da história, o conceito de pessoa foi moldado pela cultura e pela sociedade, e, consequentemente, pelo Direito, de modo que, em certos momentos, foi possível haver seres humanos excluídos do conceito de pessoa, como os escravos e as mulheres (FERREIRA, 2011, p. 343).

A ideia desenvolvidapor Kelsenfoi a de que ser pessoa para o Direito nada tem relação com ser humano, ou guardar atributos específicos da humanidade, como a racionalidade, por

${ }^{6}$ Quando o direito de alguém é demandado em juízo por um terceiro (THEODORO JR., 2014, p. 416). 
exemplo. Caso assim fosse, qual seria a justificativa para se excluir negros e mulheres do âmbito de incidência da norma que define os sujeitos de direito?

Ser pessoa para o Direito significa ter suas relações sociais valoradas como relações jurídicas, atribuindo-lhes direitos e deveres. E essa atribuição é técnica, não sentimental ou de ordem moral. Em outras palavras: o Direito escolhe quem é sujeito de direito, independentemente dos caracteres biológicos.

Neste sentido, a discussão sobre a capacidade de ser parte e de estar em Juízo dos animais não-humanos não deve partir do pressuposto da racionalidade, mas deve ser tratada considerando os pressupostos para a construção do conceito de pessoa no Direito, ainda com apoio na teoria dos casos marginais.

\subsection{Os animais em juízo em outro momento da história}

Conforme Heron de José Santana Gordilho e Tagore Trajano de Almeida Silva (2012, p. 336-337), a participação de animais em processos judiciais não é novidade. Por volta do século XVI, processos criminais e cíveis em desfavor de animais eram recorrentes. No livro "The Criminal ProsecutionandPunishmentofanimals"”, de E. P. Evans, há vários casos relatados, os quais envolveram a submissão de animais a julgamentos.

Nesses casos, a justificativa para o reconhecimento da capacidade de ser parte dos animais, inicialmente, adviria da interpretação religiosa quanto à essência deles. Antes do Cristianismo como religião oficial, o Cosmo era visto como um único ser vivo pulsante, de modo que os homens e os animais compartilhavam as mesmas características. Com a instituição do Cristianismo e a consolidação da força da Igreja Católica, o medo das trevas e da perda do apoio divino difundia nas pessoas a necessidade de realizar delações sobre os atos contrários à ordem natural, aquelescontrários às regras divinas (ABAL; CHINI, 2018, p. 138-140).

Neste cenário, passou-se a haver julgamentos de animais no âmbito não só judicial, como religioso. A demanda judicial acolhia a hipótese de os animais causarem danos físicos aos seres humanos, enquanto o julgamento religioso se dava quando os animais causavam danos de ordem exclusivamente patrimonial (LOURENÇO, 2017, p. 89). No tocante aos julgamentos religiosos, a Igreja Católica, apesar da sua eloquência, não conseguia adequadamente explicar as punições aplicadas aos animais, visto que, ao mesmo tempo em que os inferiorizava, os igualava aos seres humanos em termos de responsabilidade (ABAL; CHINI, 2018, p. 144).

${ }^{7}$ Tradução livre: O processo criminal e a punição dos animais 
Segundo Daniel Braga Lourenço (2017, p. 88), tal alternância de significado se caracterizava pela proximidade dos animais não-humanos aos homens no âmbito da vida social e privada, o que fez com que os animais passassem a ser vistos também como moral e juridicamente responsáveis pelos seus atos.

Essa responsabilidade moral advinha, inclusive, do próprio tratamento conferido pelo humano ao animal, posto que se treinava cães e cavalos, por exemplo, a partir de um método de punições e recompensas, o que fazia com que se estabelecesse um relacionamento profundo e o desenvolvimento de uma personalidade única no animal. Além disso, os animais considerados domésticos, nos séculos XVI e XVII, eram intitulados companheiros dos seus donos e permaneciam junto àqueles por um interesse compartilhado, de felicidade e bem-estar (THOMAS, 1988, p. 116-117).

Em razão desse tratamento diferenciado ${ }^{8}$ conferido aos animais, eles eram submetidos a julgamentos em cortes judiciais pela prática de crimes que, atualmente, somente são imputados aos seres humanos, como o homicídio. Apesar da incapacidade dos animais não-humanos de efetivamente realizarem sua defesa e apresentarem as razões da "realização"dos fatos ilícitos a si imputados, o processo era compostos de todos os atos "jurídicos".

O iter processual se iniciava com a apresentação da acusação por um advogado, sendo, em seguida, nomeado um defensor para os animais, uma vez queeles tinham o direito ao contraditório e à ampla defesa. Após a fase instrutória, o pleito era julgado, sendo permitidoarrolar testemunhas para esclarecimento da ocorrência. Em muitos casos, havia a condenação dos réus (animais não-humanos); todavia, também foram noticiados casos de absolvição, demonstrando que a legitimidade passiva dos animais em processos judiciais não era algo alegórico segundo a cultura da época (LOURENÇO, 2017, p. 95).

Apesar disso, a capacidade de ser parte dos animais não-humanos na Idade Média carregava em si um aspecto de misticismo, de atribuição das ocorrências à Divindade, da submissão dos acontecimentos sociais às ordens de Deus a que todos estão submetidos, inclusiveos animais (BARATELA, 2015, p. 26).Por isso, em muitos casos, a Igreja buscava justificar as pragas que abatiam as plantações a partirda realização de julgamentos religiosos de gafanhotos e insetos a fim de que a população se sentisse segura e protegida contra a ira divina.

Afora isso, a atribuição da referida capacidade em nada se relacionava com o reconhecimento de direitos em favor dos animais, uma vez que eles permaneciam sempre na posição de réus nos processos instaurados. Tal se apresentava como um contrassenso, posto que

${ }^{8}$ Fala-se no termo "diferenciado", uma vez que, nesse contexto, os animais não eram vistos como coisas, mas como seres advindos da divindade e, portanto, moralmente considerados. 
os animais não tinham, como não têm, capacidade de responder moralmente pelos seus atos, sendo pacientes morais (LOURENÇO, 2017, p. 98), equivalendo ao que no Direito Penal intitula de "inimputáveis".

Então, difundir a ideia de que o Direito, na Idade Média, reconheceu aos animais nãohumanos a capacidade de ser parte é equivocada. Os julgamentos dos animais mais tinham a ver com a necessidade de punir aqueles que se insurgiam contra o homem (LOURENÇO, 2017, p. 102). Não sabia o homem daquela época como fazer valer seu direito perante os animais e como justificar perante Deus essa punição e os atos praticados.

Como o convívio em sociedade, assim como a vida privada, tinham como centro gravitacional Deus, todas as suas criaturas se submeteriam a ele, às suas ordens e ao sistema de governo. Nessa escala de poder, o homem estava acima dos animais, mas abaixo de Deus, logo tinha que, de alguma forma, subjugar queles que lhe eram inferiores.

Somente quando essa ideia foi se esvaindo da mentalidade social, especialmente com o Renascimento e a Revolução Copernicana, o homem tomou a centralidade do pensamento científico e se apartou por completo dos animais, relegando-os ao nível das coisas, com parâmetro na racionalidade ${ }^{9}$. Logo, a sistemática processual mudou drasticamente e se tornou impensável julgar animais por crimes comuns (LOURENÇO, 2017, p. 103).

Atualmente, dada a premissa kantiana de centralidade humana no tocante à dignidade, bem como resquícios da premissa cartesiana pautada na racionalidade, em termos gerais, os animais apresentam status jurídico de coisas e, a priori, não têm capacidade de ser parte ou de estar em Juízo.

\subsection{A capacidade de ser parte dos animais a partir da Constituição Federal de 1988}

A possibilidade de atribuição de direitos aos animais em razão da disposição constitucional contida no inciso VII do $\S 1^{\circ}$ do artigo 225 tem levantado discussões no âmbito doutrinário. E isso porque na perspectiva kantiana restariam aos seres humanos somente deveres indiretos em relação aos animais, sendo o homem o centro do ordenamento jurídico e o ponto de partida para a consagração da dignidade (SARLET; FENSTERSEIFER, 2012, p. 77; KANT, 1988, p. 287-288).

\footnotetext{
${ }^{9}$ René Descartes (1596-1650), foi filósofo que desenvolveu o método intitulado de cartesiano. Em suas considerações, e ressaltando a importância da razão para a construção científica, e, assim, para a caracterização da humanidade/pessoalidade, afirmou que os animais seriam apenas autômatos, verdadeiras máquinas, sem sentimentos, autonomia e impassíveis de consideração moral (DESCARTES, 1962, p. 1-51.).
} 
Apesar disso, se torna cada vez mais premente refletir sobre o reconhecimento da dignidade dos seres vivos, e não só humana, haja vista se tratar de um valor singular, que a vida em si exala. Com efeito, a Norma Constitucional traz a proteção dos animais sob a perspectiva do reconhecimento do valor inerente a outras formas de vida que não humanas, e, inclusive, contra a própria ação dos homens. Logo, não se estaria procurando proteger o homemexclusivamente (SARLET; FENSTERSEIFER, 2012, p. 79).

Neste sentido, Vicente de Paula Ataíde Júnior (2018, p. 52) ressalta que, ao dispor sobre a proteção dos animais não-humanos contra os atos cruéis, o legislador constituinte não estava pretendendo a salvaguarda do equilíbrio ecológico, o que já estava disposto na parte inicial do inciso em discussão. Assim, a regra contida na parte final do inciso VII estaria mais bemescrita num dispositivo à parte, visto que se funda no reconhecimento da capacidade de sentir dos animais e, de igual forma, na sua dignidade enquanto seres vivos.

A vida e a dignidade dos animais não-humanos não é propriamente o âmbito de discussão em que divergem os doutrinadores, mas, sim, se, para além do aspecto moral, a eles seriam devidos direitos básicos. Embora a Constituição seja clara quanto à proibição da crueldade em desfavor dos animais, o pensamento antropocêntrico desvia a perspectiva hermenêutica para considerar que os homens se sentiriam ameaçados e violados em sua dignidade se um animal sofresse. E, mais, representaria um ato de desequilíbrio ecológico torturar um animal.

Ocorre que, como bem apontado por Luís Roberto Barroso (BRASIL, 2016, p. 41-42) e por Vicente de Paula Ataíde Júnior (2018,p. 52), quando se ingressa com uma ação direta de inconstitucionalidade perante o Supremo Tribunal Federal a fim de proibir práticas como a farra do boi, a vaquejada e a rinha de galo, assim como quando se disciplina que é crime praticar abuso, maus-tratos e mutilação contra animais, não se está pensando na manutenção do equilíbrio ecológico, tampouco que com isso se manterá o ecossistema estável. Pretende-se proteger aquele animal específico (ou grupo de animais) de atos que lhe ferem o corpo e a moral.

De outra banda, quando se discute judicialmente o ilícito das queimadas e do desmatamento, que destrói o habitat de inúmeras espécies, aí, sim, é possível falar na proteção do equilíbrio da fauna (assim como da flora), o que alcança a perspectiva do direito do homem ao meio ambiente ecologicamente equilibrado (ATAÍDE JÚNIOR, 2018, p. 52-53; BRASIL, 2016, p. $10 ; 17-18)$.

Para o Direito Animal, cada ser vivo importa, em suas particularidades e interesses, e, por isso, se se protegem os animais contra a crueldade, não se trata de uma proteção macro que alcança o homem, mas de um olhar micro, em respeito à evolução científica e social quanto ao 
status jurídico dos animais, cuja senciência e consciência já foram reconhecidas publicamente (LOW et al., 2012.).

Nesse diapasão, se os animais são capazes de sentir dor e apresentam certo nível de consciência, as normas jurídicas que a seu respeito vedam comportamentos humanos cruéis configuram verdadeiros direitos subjetivos não-humanos, haja vista que tais disposições legais não guardam liame jurídico interesses humanos diretamente.

Assim, se o processo é um valor culturalquedeve se adequar às mudanças operadas no âmbito em que se desenvolve (GORDILHO; SILVA, 2012, p. 343), e "pessoas" apresentam uma conotação estritamente técnica, isto é, ser sujeito de direitos ou pessoa para o ordenamento jurídico depende somente da vontade do legislador, mesmo que os animais não consigam expressar os seus interesses da mesma forma que os homens, não há empecilho em reconhecer a capacidade jurídica dos animais para pleitear em Juízo.

Os animais, como acima delineado, não podem mais ser considerados coisas, visto gozarem estruturas cognitivas que antes eram consideradas o limite entre o homem e tais seres (FERREIRA, 2011, p. 341).Neste sentido, Camilo Henrique Silva e Tereza Rodrigues Vieira (2014,p. 479) afirmam que não é impossível ao ordenamento jurídico brasileiro dispor sobre a legitimidade dos animais em Juízo, uma vez que tal disposição seguiria a mesma lógica da legitimidade dos incapazes, das pessoas jurídicas, da massa falida, do espólio, ou seja, bastaria que houvesse um representante humano para expor em palavras o interesse do animal.

Baseando-se nesse princípio, recentemente foram ajuizadas por animais pelo menos duas ações que chamaram a atenção do Judiciário e em cujo bojo foi posto em discussão o aspecto dalegitimidade ativa.

No estado do Paraná, na Comarca de Cascavel, o pitubull Jack ajuizou ação de reparação de danos em desfavor do seu antigo "dono" Matheus Henrique Mello, pleiteando danos morais e materiais em razão dos maus-tratos sofridos, bem como a modificação da sua guarda em favor da Organização Não-Governamental Sou Amigo (BRASIL, 2020a, p. 1).

De início, foi determinada a emenda da inicial para modificação do polo ativo da demanda. O autor, diante do despacho, se ateve a incluir como autora a ONG Sou Amigo. Assim, ao apreciar a inicial, a juíza Gabrielle Britto de Oliveira, mesmo afirmando que os animais merecem a aquisição do status de sujeitos de direitos, acentuou que o processo deveria ser extinto sem resolução do mérito em relação a Jack por ausência de capacidade jurídica (BRASIL, 2020a, p. 1).

Apesar da argumentação acima, aquele Juízo reconheceu a legitimidade da ONG Sou Amigo e lhe deferiu a "guarda" provisória do animal, tendo sido lavrado o seu termo (BRASIL, 
2020a, p. 3).Isto é, apesar de não ter reconhecido Jack como sujeito de direitos, o Juízo conferiu a "guarda" (termo jurídico aplicado estritamente à tutela de humanos) do animal à ONG sob a premissa dos maus-tratos perpetrados pelo antigo dono.

Já no estado da Bahia, na $5^{\text {a }}$ Vara Cível da Comarca de Salvador, discutiu-se o caso de vinte e três gatos, todos nominados, os quais ajuizaram ação de obrigação de fazer e indenizatória em desfavor de duas construtoras. O fato é que as rés estariam construindo empreendimento em local onde os autores teriam se habituado a receber cuidados de Camila de Jesus Dantas de Oliveira, que se intitulou sua guardiã, o que levou à restrição da possibilidade de acesso aos animais pela cuidadora, e, assim, da disponibilização de alimento e água. Diante disso, pelo menos um animal veio a óbito (BRASIL, 2020b, p. 7-29).

Inicialmente, o juiz Joanísio de Matos Dantas Júniordeterminou a designação de audiência de conciliação,na intenção de formalizar acordo entre as partes. Não tendo havido composição da lide, e tendo o Ministério Público informado não ter interesse no feito, aquele Juízo extinguiu o processo sem resolução do mérito, afirmando que os animais não possuíam capacidade de ser parte e que a autointitulada guardiã nãoera legitimada extraordinária. Da decisão foram opostos embargos declaratórios, os quais não foram acolhidos, tendo sido interposto recurso de apelação, que ainda não foi julgado (BRASIL, 2020b, p. 116-117, 129, 239240).

Vê-se que, em ambos os casos,aos animais foi negada a capacidade jurídica apesar do reconhecimento da violação de seus direitos. Num dos casos, pelo menos, observou-se o verdadeiro intuito do Judiciário em abraçar os novos valores que despontam na sociedade. Provavelmente, a falta de balizas mais claras quanto ao atendimento aos pressupostos processuais tenha levado às decisões mencionadas, mas o fato é que os atores sociaisestão passando a se posicionar em prol de uma mudança mais urgente.

Palmilhando esse caminho, alguns autores afirmam que os animais se encartariam na categoria de entes despersonalizados, uma vez que ser sujeito de direitos está além de ser pessoa. Logo, não haveria óbice na admissão em Juízo do animalcomo ente despersonalizado, substituído pelo Ministério Público ou por entidades protetoras, ou até mesmo guardiães, sendo essa a medidaque mais se aproxima da proteção efetiva dos animais como consagrado na Constituição Federal (GORDILHO; SILVA, 2012, p. 354-355).

De fato, o acesso à justiça se verifica a partir do pressuposto da consagração de um direito material, então, cabe ao direito processual efetivar, e não dificultar sem qualquer fundamento bastante o exercício dos direitos outorgados aos animais (SILVA; VIEIRA, 2014, p. 479). 
Para tanto, basta considerar o argumento dos casos marginais, que exige do interlocutor uma explicação livre de posicionamentos sobre uma disparidade moral extrema. Não é demais lembrar que já deixamos de considerar como moral e juridicamente relevante a ausência de racionalidade, autoconsciência, autonomia, reciprocidade e linguagem (NACONECY, 2014, Ebook).

Diante disso, se consideramos capazes juridicamente um ser humano em coma, uma criança, uma pessoa com anencefalia, todos inaptos em certos aspectos da vida material, por que não considerar os animais igualmente capazes quando já foi provado cientificamente serem eles portadores de certo nível de consciência?

A teoria dos casos marginas leva o interlocutor a refletir sobre os fundamentos que levam a sociedade a ainda não reconhecer os direitos dos animais, inclusive o de postular em Juízo. Num primeiro olhar, é normal reconhecer direitos a todo e qualquer animal humano, somente pelo fato de ser humano, e mesmo nos casos em que esses seres se encontram desprovidos de autonomia e racionalidade;mas, quando se usa o argumento da superioridade do homem em relação ao animal, verifica-se a fragilidade da vedação do reconhecimento dos animais como sujeitos de direitos por não serem racionais, ou não serem capazes de se expressar pela linguagem comum, já que, ao fim e ao cabo, homens e animaisapresentariam as mesmas exceções.

Logo, se os animais não possuem aptidão para pleitear por si mesmos direitos no Poder Judiciário, em razão da semelhante impossibilidade dos absolutamente incapazes, isso não significa que eles não possam proteger seus interesses através de um representante ou de um assistente (LIMA, 2014, p. 168). Para se proteger um direito, o Judiciário não pode estipular amarras, mas soltar as existentes.

Diante disso, a tese da impossibilidade jurídica dos animais serem sujeitos de direitos se apresenta inconsistente, uma vez que o interesse desses seres vivos é jurídico, sendo objeto de tutela estatal toda violação verificada e comprovada. Se é prescrito ser vedado maltratar animais, como pode o Poder Judiciário se negar a cumprir a norma, e, assim, resguardar a inviolabilidade da moral e da dignidade dos animais?

\section{CONCLUSÃO}

$\mathrm{O}$ artigo $5^{\circ}, \mathrm{XXXV}$ da Constituição Federal dispõe que cabe ao Judiciário apreciar toda e qualquer lesão ou ameaça de lesão a direito. Apesar de atualmente ser um direito proclamado a todos, independentemente da raça, cor, gênero, sexo, classe, a sua acepção inicial, além de 
meramente objetiva, não abarcava todos aqueles que necessitavam diretamente de proteção estatal.Negros, mulheres, escravos, índios, tiveram que conquistar seu espaço no ambiente jurídico; as lutas foram árduas e procedimentais: primeiro a aquisição de direitos materiaissubjetivos, depois o direito de pleitear a sua proteção em Juízo.

Nesse contexto, a luta pelos direitos dos animaisnão apresenta tamanha diferença (se poderia objetar que o pleito é humano, e não animal; para contra-argumentar, basta lembrarmos que os pais pleiteiam em favor dos filhos e os tutores e curadores em favor de seus tutelados e curatelados): primeiro foram consagrados direitos, agora se busca uma forma de assegurá-los em Juízo.

A alteração de paradigma trazida pela Constituição Federal de 1988 trouxe a necessidade de repensar conceitos e institutos jurídicos há muito estanques neste âmbito. Os conceitos de sujeitos de direito, pessoa, personalidade jurídica, capacidade de ser parte, etc. exigem novo olhar para se adequarem aos direitos que estão surgindo e, principalmente, aos seus titulares.

De fato, se o próprio ordenamento jurídico optou por conferir aos animais direitos subjetivos, não há logicidade em negar-lhe a capacidade de buscar a sua proteção perante o Poder Judiciário. Quando falamos da finalidade do direito processual sempre relacionamos com a concretização dos direitos materiais, no caso dos animais não seria diferente.

A defesa dos direitos dos animais em juízo representa um meio de emancipação desses seres diante da visão antropocêntrica do homem, que os ainda submete à situação de coisas, desprovidos de sentimentos e sensações. Diferentemente do que se viu na Idade Média, em que, sob o véu da semelhança dos homens e animais, esses últimos foram julgados pelos danos causados, mesmo não tendo capacidade de compreender a sua ação, atualmente, reconhecendo as diferenças e, nisso, as particularidades e interesses dos animais, é possível pensar num processo em que os animais sejam partes.

Esses seres, assim como os homens, possuem senciência e consciência, e precisam que seus interesses sejam preservados não somente por via transversa, como se pretende a maioria dos julgadores; mas, é premente o exercício imediato de seus direitos, visto que, ao ser maltratado, não é o homem quem sofre ou tem sua moral abalada, e, sim, os animais.

Logo, se para ser considerado sujeito de direitos no ordenamento jurídico não é preciso ser efetivamente uma pessoa, na acepção biológica do termo, e, se os seres humanos considerados incapazese até os entes despersonalizados podem demandar em Juízo através de um representante processual, o critério para o acesso efetivo à justiça não está calcado na aptidão 
para demandar por si próprio no Judiciário, ou ser capaz de expressar seus interesses de forma clara e por linguagem adequada.

Sabendo que o argumento dos casos marginais coloca em xeque a alegação de que os animais não são capazes de compreender a amplitude de seus direitos e não podem conscientemente contrair obrigações, e, por isso, não podem gozar de capacidade de direito ou de ser parte, uma vez que seres humanos em iguais condições não são extirpados do rol de sujeitos de direitos, tampouco se deixa de lhe conferir dignidade.

Todos esses apontamentos levam ao entendimento de que os animais não-humanos são capazes de ser parte em processos que envolvam seus direitos e interesses; a eles já foram outorgados direitos subjetivos, que não se confundem com o direito do homem ao meio ambiente ecologicamente equilibrado; por isso, se eles não têm aptidão para demandar outrem por si mesmos, nem por isso perdem essa faculdade. É possível por meio da representação ou da substituição processual adequar a técnica processual e, assim, conferir o instrumento necessário à emancipação desses seres; basta uma revisitação ao conceitos-chaves da processualística.

\section{REFERÊNCIAS}

ABAL, Felipe Cittolinl; CHINI, Mariana. O julgamento de animais na obra de E. P. Evans. Revista Duc In Altum Cadernos de Direito, Recife, v. 10, 20, p. 135-151, jan.-abr.2018. Disponível em: http://www.faculdadedamas.edu.br/revistafd/index.php/cihjur/article/view/690. Acesso em:14 jun. 2020.

ALVIM, José Eduardo Carreira. Teoria Geral do Processo.19 ed. rev., atual e ampl. Rio de Janeiro: Forense, 2016.

ATAIDE JUNIOR, Vicente. Introdução ao Direito Animal Brasileiro. Revista Brasileira de Direito Animal, Salvador, v. 13, n. 3, p.48-76, 8 nov. 2018. Universidade Federal da Bahia. DOI: http://dx.doi.org/10.9771/rbda.v13i3.28768. e-ISSN: 2317-4552. Disponível em: https://rigs.ufba.br/index.php/RBDA/article/view/28768. Acesso em: 13 jun. 2020.

\section{BARATELA, Daiane Fernandes. A proteção jurídica da fauna à luz da Constituição}

Brasileira. 2015. Dissertação (Mestrado em Direito Constitucional) - Pontifícia Universidade Católica de São Paulo, São Paulo, 2015.

BRASIL. [Constituição (1988)]. Constituição Federal. Brasília: Senado Federal, 1988. Disponível em: http://www.planalto.gov.br/ccivil_03/constituicao/constituicao.htm. Acesso em: 22 abr. 2020.

\section{BRASIL. Supremo Tribunal Federal (Plenário). Ação Direta de Inconstitucionalidade no} 4.983. Processo Objetivo - Ação Direta de Inconstitucionalidade - Atuação do Advogado-Geral da União. Vaquejada - Manifestação Cultural - Animais - Crueldade Manifesta - Preservação da Fauna e da Flora - Inconstitucionalidade. Requerente: Procurador-Geral da República. Interessados: Assembleia Legislativa do Estado do Ceará e Governador do Estado do Ceará. 
Relator: Ministro Marco Aurélio, 06 de outubro de 2016. Disponível em:

http://portal.stf.jus.br/processos/downloadPeca.asp?id=311683661\&ext=.pdf. Acesso em: 08 dez. 2020 .

BRASIL. Tribunal de Justiça do Paraná. Decisão Interlocutória 0000691-32.2020.8.16.0021. $4^{\mathrm{a}}$ Vara Cível de Cascavel. Juíza: Gabrielle Britto de Oliveira, 04 de março de 2020a. Disponível em: https://projudi.tjpr.jus.br/projudi_consulta/. Acesso em: 09 dez. 2020.

BRASIL. Tribunal de Justiça da Bahia. Processo 8000905-50.2020.8.05.0001. $5^{\text {a }}$ Vara Cível da Comarca de Salvador. Autor: Camila de Jesus Dantas de Oliveira; Réus: Civil Construtora LTDA. e BEEL - Barcino Esteve Construções e Incorporações LTDA. Juiz: Joanísio de Matos Dantas Júnior, 2020b. Disponível em: https://consultapublicapje.tjba.jus.br/pjeweb/ConsultaPublica/DetalheProcessoConsultaPublica/listView.seam?ca=af04b8907ffb7150812 5733ef0d4f40021983bbb885681ec. Acesso em: 20 dez. 2020.

BARREIROS, Lorena Miranda Santos. Breves considerações sobre o princípio do acesso à justiça no Direito brasileiro. Revista Direito UNIFACS, Salvador, n. 112, out./2009. ISSN 1808-4435. p. 1-30. Disponível em: https://revistas.unifacs.br/index.php/redu/article/view/835. Acesso em: 13 jun. 2020.

BONAVIDES, Paulo. Curso de Direito Constitucional. 26. ed. São Paulo: Malheiros Editores, 2011. $835 \mathrm{p}$.

CANOTILHO, José Joaquim Gomes. Direito Constitucional e Teoria da Constituição. 7. ed. Coimbra: Almedina, 2003. 1522 p.

CAPPELLETTI, Mauro; GARTH, Bryant. Acesso à Justiça. Tradução: Ellen Gracie Northfleet. Porto Alegre: Fabris, 1988. 168 p.

CARTA FORENSE. Direito Animal: Expectativas Constitucionais. Jornal Carta Forense. São Paulo, 01 jun. 2017 [online]. Disponível

em:http://www.cartaforense.com.br/conteudo/entrevistas/direito animal expectativas constitucionais/17619. Acesso em: 22 abr. 2020.

CHIOVENDA, Giuseppe. Instituições de direito processual civil. Campinas: Bookseller, $2009.1323 \mathrm{p}$.

COELHO, Fábio Ulhoa. Curso de direito civil: parte geral. 5 ed. São Paulo: Saraiva, 2012.v. 1.

DESCARTES, René. Discurso do Método: Para bem conduzir a própria razão e procurar a verdade nas ciências. In: GUINSBURG, Jacob; PRADO JUNIOR, Bento (org.). Obras Escolhidas. São Paulo: Difel - Difusão Europeia do Livro, 1962. p. 1-51.

FARIAS, Cristiano Chaves de; ROSENVALD, Nelson. Curso de Direito Civil: parte geral e LINDB. 13 ed. São Paulo: Atlas, 2015. 752 p. v. 1.

FERREIRA, Ana Conceição Barbuda. Animais não humanos como Sujeitos de Direito: considerações processuais. Revista Brasileira de Direito Animal, Salvador, v. 6, n. 9, p. 307 353, 21 jul. 2011. Universidade Federal da Bahia. DOI: http://dx.doi.org/10.9771/rbda.v6i9.1173. Disponível em: https://periodicos.ufba.br/index.php/RBDA/article/view/11733. Acesso em: 13 jun. 2020. 
GONÇALVES, Carlos Roberto. Direito Civil Brasileiro:parte geral. 10 ed. São Paulo: Saraiva, 2012.v. 1.

GOUVEIA FILHO, Roberto Pinheiro Campos. A capacidade postulatória como uma situação jurídica processual simples: ensaio em defesa de uma teoria das capacidades em direito. 2008 . Dissertação (Mestrado em Direito) - Universidade Católica de Pernambuco, Recife, 2008.

GORDILHO, Heron José de Santana; SILVA, Tagore Trajano de Almeida. Animais em Juízo: Direito, Personalidade Jurídica e Capacidade Processual. Revista de Direito Ambiental,v. 65, p. 333-362, jan. 2012. Disponível em:

https://papers.ssrn.com/sol3/papers.cfm?abstract_id=2352064. Acesso em: 13 jun. 2020.

KANT, Immanuel. Lecciones de Ética. Barcelona: Editorial Crítica, 1988. 307 p.

KELSEN, Hans. Teoria Pura do Direito. São Paulo: Martins Fontes, 1999. 271 p.

LIMA, Fernando Bezerra de Oliveira. Habeas Corpus para animais: admissibilidade do HC "Suíça". Revista Brasileira de Direito Animal, Salvador, v. 2, n. 3, p. 155-192, 20 maio 2014. Universidade Federal da Bahia. DOI: http://dx.doi.org/10.9771/rbda.v2i3.10362. Disponível em: https://periodicos.ufba.br/index.php/RBDA/article/view/10362. Acesso em: 20 abr. 2020.

LIMA, George Marmelstein. O direito fundamental à ação. Fortaleza, 1999. 183 p.

LOURENÇO, Daniel Braga. A persecução e a condenação criminal de animais: o processo judicial como meio de conferir integridade às narrativas sociais em conflito. Revista Brasileira de Direito Animal, Salvador, v. 12, n. 02, p. 85-123, 24 jul. 2017. Universidade Federal da Bahia. DOI: http://dx.doi.org/10.9771/rbda.v12i02.22944. Disponível em:

https://periodicos.ufba.br/index.php/RBDA/article/view/22944. Acesso em: 13 jun. 2020.

LOW, Philip et al. The Cambridge DeclarationonConsciousness.Cambridge, Reino Único, 7 jul. 2012. Disponível em:

http://fcmconference.org/img/CambridgeDeclarationOnConsciousness.pdf. Acesso em: 11 jun. 2020 .

MONNERAT, Fábio. Introdução ao estudo do Direito Processual Civil. 5. ed. São Paulo: Saraiva Educação, 2020. 616 p.

NACONECY, Carlos Michelon. Ética \& Animais: um guia de argumentação filosófica. 2 ed. Porto Alegre: EDIPUCRS, 2014. Ebook.

NEVES, Daniel Amorim Assumpção. Manual de Direito Processual Civil.9 ed. Salvador: Ed. Juspodivm, 2017. 1808 p.

SARLET, Ingo Wolfgang; FENSTERSEIFER, Tiago. Direito Constitucional Ambiental: Constituição, direitos fundamentais e proteção do ambiente. 2. ed. São Paulo: Revista dos Tribunais, 2012. $384 \mathrm{p}$.

SARLET, Ingo Wolfgang; MARINONI, Luiz Guilherme; MITIDIERO, Daniel. Curso de direito constitucional. 4. ed. São Paulo: Saraiva, 2015. 


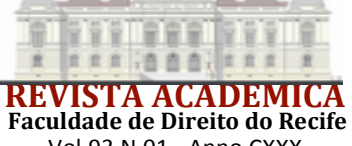

Faculdade de Direito do Recife

Vol.93 N.01 - Anno CXXX

SILVA, Camilo Henrique; VIEIRA, Tereza Rodrigues. Tutela Jurídica dos Animais NãoHumanos no Brasil. Revista Jurídica CESUMAR,Paraná, v. 14, n. 2, p. 469-489, 23 set. 2014. UniCesumar. ISSN 2176-9184. Disponível em:

https://periodicos.unicesumar.edu.br/index.php/revjuridica/article/view/3720. Acesso em: 04 abr. 2020.

SILVA, Juvêncio Borges. O acesso à justiça como direito fundamental e sua efetivação jurisdicional. Revista de Direito Brasileira, Florianópolis, v. 4, n. 3, set./2013, p. 478-503. ISSN 2358-1352. DOI: http://dx.doi.org/10.26668/IndexLawJournals/23581352/2013.v4i3.2648. Disponível em:

https://www.indexlaw.org/index.php/rdb/article/view/2648. Acesso em: 10 abr. 2020.

TAVARES, André Ramos. Curso de direito constitucional. 18. ed. São Paulo: Saraiva Educação, 2020. 1240 p.

THEODORO JR., Humberto. Curso de Direito Processual Civil: Teoria geral do direito processual civil e processo de conhecimento. Rio de Janeiro: Forense, 2014. v. 4.

THOMAS, Keith. O homem e o mundo natural: mudanças de atitude em relação às plantas e aos animais (1500-1800). Tradução de João Roberto Martins Filho. São Paulo: Companhia das Letras, 1988. $454 \mathrm{p}$. 